\begin{tabular}{ccc}
\hline International Journal of Engineering \& Technology, $7(3.11)(2018) 121-125$ \\
SPC \\
Website: www.sciencepubco.com/index.php/IJET \\
Research paper
\end{tabular}

\title{
Understanding the Electronic Transition of Normal Spinel Structure of Co3O4 Using GGA+U Calculations
}

\author{
N.H.M Zaki ${ }^{1,2}$, M. Mustaffa ${ }^{1}$, M.F.M. Taib ${ }^{1}$, O.H.Hassan ${ }^{3}$, M.Z.A.Yahya ${ }^{4}$, A.M.M.Ali ${ }^{1,2}$ \\ ${ }^{1}$ Faculty of Applied Sciences, Universiti Teknologi MARA 40450 Shah Alam, Selangor MALAYSIA \\ ${ }^{2}$ Institute of Sciences, Universiti Teknologi MARA 40450 Shah Alam, Selangor MALAYSIA \\ ${ }^{3}$ Department of Industrial Ceramic, Faculty of Art and Design, Universiti Teknologi MARA, 40450 Shah Alam, Selangor \\ MALAYSIA \\ ${ }^{4}$ Faculty of Defence Science \& Technology, Universiti Pertahanan Nasional Malaysia, 57000 Kuala Lumpur, MALAYSIA \\ *Corresponding author E-mail: hamizah.zaki@gmail.com
}

\begin{abstract}
The normal spinel cobalt oxide $\mathrm{Co} 3 \mathrm{O} 4$ is considered as a magnetic semiconducting material comprising of cobalt ions with two oxidation states of $\mathrm{Co} 2+$ and $\mathrm{Co} 3+$. Density Functional Theory (DFT) calculation are employed to generate the structural, electronic and optical properties using Generalized Gradient Approximation (GGA) function. The Perdew-Burke-Ernzerh for solids (PBEsol) exchangecorrelation functional approach successfully predict the semiconductor behaviour of $\mathrm{Co} 3 \mathrm{O} 4$ but severely underestimates the band gap in relation to the experimental value. The GGA+U is performed in order to treat the Co-3d states and achieve the band gap of $1.26 \mathrm{eV}$ which agrees with the experimental results. For optical studies, here we unveil the predicted three assumed electron transition occurring in $\mathrm{Co} 3 \mathrm{O} 4$ for $\mathrm{O}(2 \mathrm{p}) \rightarrow \mathrm{Co} 2+(\mathrm{t} 2 \mathrm{~g}), \mathrm{O}(2 \mathrm{p}) \rightarrow \mathrm{Co} 3+(\mathrm{eg})$ and $\mathrm{Co} 3+(\mathrm{t} 2 \mathrm{~g}) \rightarrow \mathrm{Co} 2+(\mathrm{t} 2 \mathrm{~g})$.
\end{abstract}

Keywords: Generalized Gradient Approximation (GGA); Hubbard U; Co3O4; Electronic Properties; Optical Properties

\section{Introduction}

The intriguing physical properties, high capacitance $(\sim 3650 \mathrm{Fg}$ $1)$, excellent chemical behaviour, cost-effective and environmental friendliness of $\mathrm{Co} 3 \mathrm{O} 4$ has drawn extensive research interests. This is due to the many potential applications as electrodes, such as a catalyst for oxygen evolution and oxygen reduction [1], sensors [2], Li-ion batteries [3] and supercapacitors [4 - 5]. From a theoretical point of view, the cubic crystalline structure of $\mathrm{Co} 3 \mathrm{O} 4(\mathrm{Fd} 3 \mathrm{~m})$ is a challenging material because of two distinct $\mathrm{Co}$ sites due to two oxidation states of $\mathrm{Co} 2+$ and $\mathrm{Co} 3+$. This two-formula-unit face-centered-cubic material (FCC) can be expressed as $\mathrm{AB} 2 \mathrm{O} 4$ (A: tetrahedral, B: octahedral). The tetrahedral sites, (A) occupied by high spin (HS) Co2+ (d7) ions and octahedral sites (B) occupied by low spin (LS) Co3+ (d6) ions. Experimentally, the $\mathrm{Co} 2+$ ion has a magnetic moment of $3.0 \mu \mathrm{B}$ while $\mathrm{Co} 3+$ is non-magnetic. The magnetic properties are governed by $\mathrm{Co} 2+$ ion due to unoccupied state in $\mathrm{t} 2 \mathrm{~g}$ orbital according to its electronic configuration $\mathrm{t} 32 \mathrm{~g}(\uparrow) \mathrm{t} 02 \mathrm{~g}(\downarrow) \mathrm{e} 2 \mathrm{~g}(\uparrow) \mathrm{e} 2 \mathrm{~g}(\downarrow)$ while, Co3+ ion

completely filled the $\mathrm{t} 2 \mathrm{~g}$ level [6]. The electronic configuration of $\mathrm{Co} 3+$ is $\mathrm{t} 32 \mathrm{~g}(\downarrow) \mathrm{t} 32 \mathrm{~g}(\uparrow) \mathrm{e} 0 \mathrm{~g}(\uparrow) \mathrm{e} 0 \mathrm{~g}(\downarrow)$. Various experimental methods and theoretical studies have been conducted to provide a better understanding of the electronic and optical properties [7 - 9] of this material, which constitute different interpretations of optical absorption spectrum related to its electron transition.

Three assumed electron transition is said to occur; including $\mathrm{p}$ and d orbital (Figure 1): two pathways from ligand $\mathrm{O}(2 \mathrm{p})$ to metal charge transfer of cobalt cations (LMCT), transition between two metal to metal with different cobalt oxidation states (MMCT), and one d-d ligand field excitation within each of the $\mathrm{Co} 2+$ and $\mathrm{Co} 3+$ cations. According to Marten et al. [9] by using spectroscopy ellipsometry, the optical transition in $\mathrm{Co} 3 \mathrm{O} 4 \mathrm{ob}-$ tained at $0.80,1.60,2.65$, and $4.40 \mathrm{eV}$ are pertaining to electronic transition of $\mathrm{Co} 2+\rightarrow \mathrm{Co} 3$. As time elapsed, Kim and Park [10] have proposed more details of the three optical transition located at $1.65,2.40$ and $2.80 \mathrm{eV}$ from dielectric function result corresponding to $\mathrm{Co} 3+(\mathrm{t} 2 \mathrm{~g}) \rightarrow \mathrm{Co} 2+(\mathrm{t} 2 \mathrm{~g}), \quad \mathrm{O}(2 \mathrm{p}) \rightarrow \mathrm{Co} 2+(\mathrm{t} 2 \mathrm{~g})$, and $\mathrm{O}(2 \mathrm{p}) \rightarrow \mathrm{Co} 3+(\mathrm{eg})$ respectively. However, $\mathrm{Xu}$ et al. [11] has disagreed with previous work and proposed another energy level performed by first principle studies (DFT) using GGA-PBE exchange-correlation. The variation of the different perceptions of charge transition in $\mathrm{Co} 3 \mathrm{O} 4$ has led to the present work explained from a theoretical view.

Thus, in this work, we present the structural parameters, band structures, the density of states (DOS) and optical studies (dielectric function) by first principle calculation in normal spinel 
Co3O4. The purpose of the study is to go beyond understanding of pure $\mathrm{Co} 3 \mathrm{O} 4$ based on optical absorption.

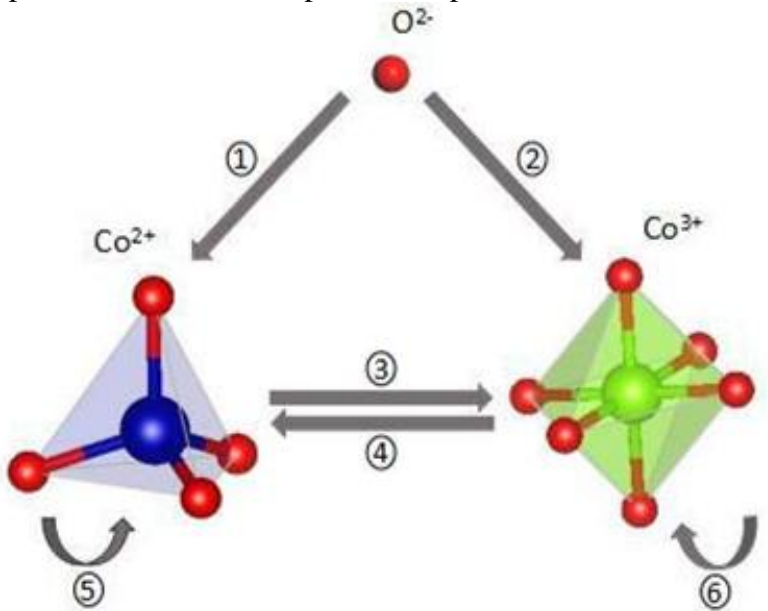

Figure 1 Types of charge transition, $(1,2)$ ligand to metal chargetransfer, $(3,4)$ metal to metal charge transfer, $(5,6) \mathrm{d}-\mathrm{d}$ intraband transition

\section{Method and Calculation Details}

All the calculations have been carried out by spin-polarized quantum mechanical calculation within scalar relativistic treatment by using density functional theory (DFT) as implemented in the Cambridge Serial Total Energy Package (CASTEP) program package in Material Studio of Accelrys Inc [12]. Periodic DFT calculations were treated within the Kohn-Sham schemes of the local density approximation by Ceperley and Alder [13] as parameterized by Perdew and Zunger [14] (LDA-CAPZ) and semi-local generalized gradient approximation (GGA) exchange-correlation functional of the Perdew-Wang91 [15] (PW91), Perdew-Burke-Ernzerh (PBE) [16] and for solids [17] (PBEsol) for all geometry optimizations. The calculation proceeded with the GGAPBEsol functional due to better description of structure than others. The plane-wave basis with a kinetic energy cutoff of $380 \mathrm{eV}$ and the Monkhorst-Pack grid with $6 \times 6 \times 6 \mathrm{k}$-point mesh to obtain well-converged sampling of the Brillouin zone.

The electronic minimization parameter of the total energy/atom convergence tolerance was $5.0 \times 10-6 \mathrm{eV}$. Ultrasoft pseudopotentials were employed where valence electron include $\mathrm{O} 2 \mathrm{~s}, 2 \mathrm{p}$, and Co $3 \mathrm{~d}$ states. The highly correlated $3 \mathrm{~d}$ orbitals of Co has to be corrected by performing the calculation using DFT+U. The Hubbard $\mathrm{U}$ values performed by single $\mathrm{U}$ is $3.5 \mathrm{eV}$ resulting in the same region with the experimental value. As such, the chosen values of $U$ is $3.5 \mathrm{eV}$.

\section{Results and Discussion}

\section{Structural Properties}

$\mathrm{Co} 3 \mathrm{O} 4$ is classified as normal cubic spinel structure with the space group of $(227 \mathrm{Fd} 3 \mathrm{~m})$. The relaxed structure of the cubic is shown in Figure 2. Two oxidation states occur in $\mathrm{Co} 3 \mathrm{O} 4$ which are divalent $(\mathrm{Co} 2+)$ and trivalent $(\mathrm{Co} 3+)$ possessed due to tetrahedral and octahedral structure respectively. The divalent ions with $\mathrm{AO} 4$ coordination exhibit in a high-spin (HS) state coupling with four neighbours of the same kind via the antiferromagnetic (AFM) ordering. Otherwise, the trivalent ions adopt a low-spin (LS) state. The lattice parameters optimized with different functionals are compared in Table 1. In general, the results of $\mathrm{Co} 3 \mathrm{O} 4$ calculated using the LDA-CAPZ functional underestimates all the lattice parameters, while the GGA functional overestimates them. Among the tested functionals, GGA-PBEsol shows the best agreement with the crystallograph- ic parameters with percentage difference of less than $\sim 1 \%$. The optimized structure with lattice constant, $\mathrm{Co}-\mathrm{O}$ bond length and magnetic moment values are presented in Table 2 .

Table 1: Calculated lattice parameters and cell volumes of normal spinel Co3O4 local functional LDA-CAPZ and semi-local functional GGAPBE, GGA-PW91 and GGA-PBEsol in comparison with the experimental values and other theoretical work. Values in the parentheses represent the percentage difference from available experimental data in references.

\begin{tabular}{|c|c|c|c|}
\hline & Method & Lattice Parameter, a $(\AA ̊)$ & Volume $\left(\AA^{3}\right)$ \\
\hline \multirow{2}{*}{$\mathrm{Co}_{3} \mathrm{O}_{4}$} & GGA-PBE & 8.197 & 550.727 \\
\hline & & $(1.61 \%)^{\mathrm{a}}$ & $(4.91 \%)^{\mathrm{a}}$ \\
\hline & & $(1.40 \%)^{b}$ & $(4.24 \%)^{\mathrm{c}}$ \\
\hline & & $(1.89 \%)^{\mathrm{c}}$ & \\
\hline & GGA-PW91 & 8.186 & 548.562 \\
\hline & & $(1.48 \%)^{\mathrm{a}}$ & $(4.50 \%)^{a}$ \\
\hline & & $(1.26 \%)^{b}$ & $(3.83 \%)^{\mathrm{c}}$ \\
\hline & & $(1.75 \%)^{\mathrm{c}}$ & \\
\hline & GGA-PBEsol & 8.087 & 528.984 \\
\hline & & $(0.25 \%)^{\mathrm{a}}$ & $(0.77 \%)^{\mathrm{a}}$ \\
\hline & & $(0.04 \%)^{b}$ & $(0.13 \%)^{\mathrm{c}}$ \\
\hline & & $(0.04 \%)^{\mathrm{c}}$ & \\
\hline & LDA-CAPZ & 7.991 & 510.418 \\
\hline & & $(-0.93 \%)^{\mathrm{a}}$ & $(-2.76 \%)^{\mathrm{a}}$ \\
\hline & & $(-1.14 \%)^{b}$ & $(-3.39 \%)^{\mathrm{c}}$ \\
\hline & & $(-0.66 \%)^{c}$ & \\
\hline & Experimental & & \\
\hline & Ref.[18] a & 8.084 & 528.320 \\
\hline & Ref.[19] & 8.080 & \\
\hline & $\operatorname{Ref} .[8]^{c}$ & & 529.600 \\
\hline & Theory & & \\
\hline & GGA-PBE [20] $^{\mathrm{d}}$ & 8.190 & 549.35 \\
\hline & GGA-PBE [21] $]^{\mathrm{e}}$ & 8.110 & - \\
\hline & GGA-PBE $[11]^{\mathrm{f}}$ & 8.084 & - \\
\hline
\end{tabular}

${ }^{\mathrm{a} X}$-Ray diffraction analysis samples by spray pyrolysis technique

${ }^{b} \mathrm{X}$-Ray diffraction analysis samples prepared by thermal decomposition

${ }^{c} \mathrm{X}$-Ray diffraction analysis at low pressure $(0 \mathrm{GPa}<\mathrm{P}<17 \mathrm{GPa})$

${ }^{\mathrm{d}}$ Quantum Espresso package using norm conserving pseudopotential

${ }^{\mathrm{e}} \mathrm{VASP}$ code program

${ }^{\mathrm{f}}$ Dmol3 program with double-numerical basis with polarization functions (DNP)

Table 2: Details on calculated data for $\mathrm{Co} 3 \mathrm{O} 4$ as given by $\mathrm{PBE}$ and $\mathrm{PBE}+\mathrm{U}$ calculation

\begin{tabular}{|c|c|c|}
\hline & PBE & $\mathrm{PBE}+\mathrm{U}$ \\
\hline Lattice constant $(\mathrm{a}=\mathrm{b}=\mathrm{c})$ & 8.087 & 8.136 \\
\hline Volume $\left(\mathrm{A}^{3}\right)$ & 528.98 & 538.65 \\
\hline Distance $\mathrm{Co}^{2+}-\mathrm{O}^{2-}$ & 1.92 & 1.95 \\
\hline Distance $\mathrm{Co}^{3+}-\mathrm{O}^{2-}$ & 1.93 & 1.93 \\
\hline $\begin{array}{l}\text { Magnetic moment } \mathrm{Co}^{2+} \\
(\mu \mathrm{B})\end{array}$ & 2.37 & 2.66 \\
\hline $\begin{array}{l}\text { Magnetic moment } \mathrm{Co}^{3+} \\
(\mu \mathrm{B})\end{array}$ & \multirow[b]{2}{*}{0.00} & \multirow[b]{2}{*}{0.00} \\
\hline & & \\
\hline
\end{tabular}



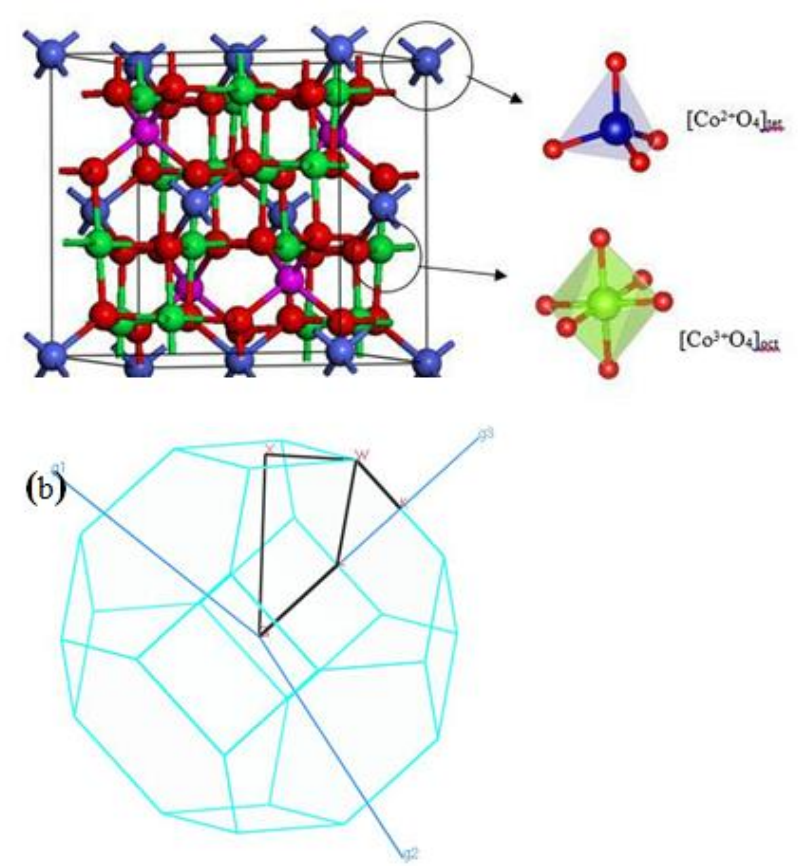

Figure 2 : Crystal structure of (a) cubic ( $\mathrm{Fd} 3 \mathrm{~m}$ ) with two inequivalent Co ions, $\mathrm{Co} 2+$ with tetrahedrally coordinated oxygen and $\mathrm{Co} 3+$ with octahedrally coordinated oxygen (polyhedron). (b) The high symmetry points within the Brillouin zone in primitive cell

\section{Electronic and Magnetic Properties}

Using the PBEsol functional, the electronic band structure was calculated along various symmetry points applied on the lattice structure within Brillouin zone at the point $\mathrm{W}(0.500,0.250$, 0.750), $\mathrm{L}(0.500,0.500,0.500), \mathrm{G}(0.000,0.000,0.000), \mathrm{X}(0.500$, $0.000,0.500)$, and $\mathrm{K}(0.375,0.375,0.750)$ as demonstrated in Figure 3. The GGA-PBEsol approach results in minimum band gap of $0.11 \mathrm{eV}$ predicted for $\mathrm{Co} 3 \mathrm{O} 4$, which severely underestimates the band gap values in semiconductor reported to be comparable to the experimental result obtained in the range of 1-1.9 $\mathrm{eV}$ [7][22]. In order to obtain a valid band gap, Hubbard $\mathrm{U}$ is included to treat the Co-3d states [15]. The PBE+U method using single $\mathrm{U}=3.5 \mathrm{eV}$ for $\mathrm{Co} 2+$ and $\mathrm{Co} 3+$ respectively gives a minimum band gap of $1.26 \mathrm{eV}$, which is in agreement with the experimental data and previous calculation performed using other exchange-correlation potentials as stated in Table 3. The inclusion of Hubbard U parameter might correct the band gap, which is an ad-hoc correction scheme and significantly .......... $\mathrm{Co} \mathrm{d}$ and $\mathrm{O} 2 \mathrm{p}$ states hybridize strongly [23].
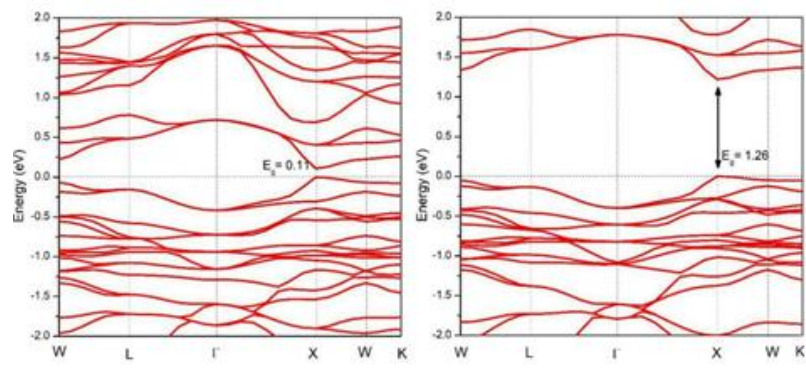

Figure 3 Calculated total band structures for $\mathrm{Co}_{3} \mathrm{O}^{4}$ obtained by (a) $\mathrm{PBE}$ and (b) $\mathrm{PBE}+\mathrm{U}$ functional with $\mathrm{U}=3.5$ for both $\mathrm{Co}^{2+}$ and $\mathrm{Co}^{3+}$. Fermi energy is set to 0

Table 3 Comparison of calculated and experimental values of the band gap $(\mathrm{eV})$ of $\mathrm{Co3O} 4$

\begin{tabular}{||l|c|c|c|c|}
\hline & Direct & & Indirect & \\
\hline & $\mathrm{X} \rightarrow \mathrm{X}$ & $\Gamma \rightarrow \Gamma$ & $\Gamma \rightarrow \mathrm{X}$ & $\mathrm{X} \rightarrow \Gamma$ \\
\hline This study & 1.26 & 2.22 & 1.77 & 1.61 \\
\hline Calculated GGA-PBE+U & & & & \\
\hline Ref [24] & 1.23 & 1.67 & 1.51 & - \\
\hline
\end{tabular}

\begin{tabular}{||l|c|c|c|c|}
\hline Ref [25] & 1.96 & 3.25 & 2.41 & 2.81 \\
\hline Experimental & & & & \\
\hline Ref [22] & 1.60 & & 2.10 & \\
\hline
\end{tabular}

Figure 4 clearly shows the essential notions of partial density of states (PDOS) of Co3O4. PDOS are represented with spin polarization for the majority and minority spin states, namely, spin up and spin down respectively. For the $\mathrm{Co} 2+$ ions, it can be seen that the majority spin $\mathrm{d}$ states are split between the eg states $(-5.5 \mathrm{eV})$ and $\mathrm{t} 2 \mathrm{~g}$ states $(-2.5 \mathrm{eV})$. The filled minority spin eg states are situated at the top of valence band while unoccupied minority $\mathrm{t} 2 \mathrm{~g}$ states dominate at the bottom of the $\mathrm{CB}$ at $(+2 \mathrm{eV})$. However, Co3+ PDOS demonstrated it is almost symmetrical with respect to the majority and minority spin states. The $\mathrm{Co} 3+\mathrm{t} 2 \mathrm{~g}$ states are concentrated at the top of the VB about $(-1 \mathrm{eV})$. The crystal field effect is nicely described by PDOS calculations (Figure 5). By referring to ' $\mathrm{A}$ ' point $(-5 \mathrm{eV})$, hybridization occurred through oxygen with the tetrahedral $\mathrm{Co} 2+3 \mathrm{~d}$ states. While at point 'B', for $\mathrm{Co} 3 \mathrm{O} 4 \mathrm{cou}-$ pling between the octahedral Co $3 \mathrm{~d}$ states with $\mathrm{O} 2 \mathrm{p}$ results in a significant amount of oxygen $\mathrm{p}$ based $\mathrm{CB}$ at $+3 \mathrm{eV}$. From PDOS analysis, Xu et al described the electronic transition bands but they reported the transition of $\mathrm{Co} 3+(\mathrm{t} 2 \mathrm{~g}) \rightarrow \mathrm{Co} 2+(\mathrm{t} 2 \mathrm{~g})$ for the $3.3 \mathrm{eV}$ absorption to be larger than experimental $(1.65 \mathrm{eV})$. In this study, optical studies conducted will show comparable results with the experimental result.

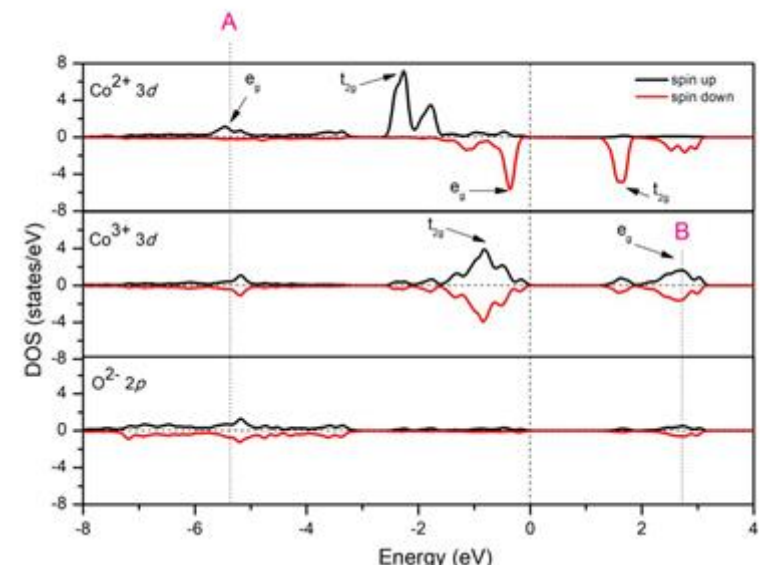

Figure 4 The projected DOS of $\mathrm{Co} 3 \mathrm{O} 4$ with references valence band maximum set at $0 \mathrm{Ev}$

(a)

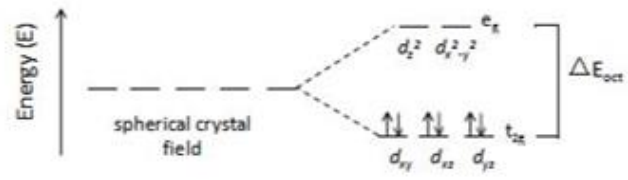

(b)

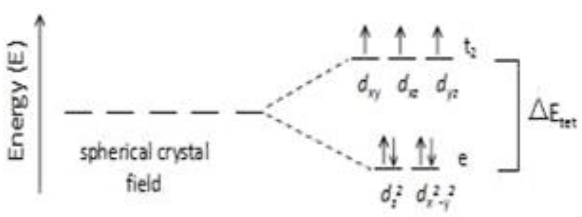

Figure 5 Schematic view of crystal field splitting of Co-3d states in $\mathrm{Co} 3 \mathrm{O} 4$

\section{Optical Studies}

The optical properties of matter can be described by the complex dielectric function $\varepsilon(\omega)$, which presents the linear response of the system to an external electromagnetic field with a small wave vector. It can be expressed as

$$
\varepsilon(\omega)=\varepsilon_{1}(\omega)+i \varepsilon_{2}(\omega)
$$

The imaginary part of the dielectric function $\varepsilon_{2}(\omega)$ is calculated by the sum of all possible direct transitions from the occupied to unoccupied states over the Brillouin zone [26].

The imaginary part $\varepsilon_{2}(\omega)$ can be calculated from the electronic structure based on the DOS given; 


$$
\varepsilon_{2}=\left.\frac{2 e \pi}{\Omega \varepsilon_{0}} \sum_{k, v, c}\left\langle\left.\left._{\psi_{k}} c\right|_{u r}\right|_{\psi_{k}}{ }^{v}\right\rangle\right|^{2} \begin{array}{cc}
c & v \\
\delta\left(E_{k}-E_{k}\right. & -E)
\end{array}
$$

Wherein $e$ refers to electron charge, and $\psi^{\varepsilon}$ and $\psi^{\mathrm{v}}$ are the CB and VB wave functions at $k$, respectively. The real and imaginary dielectric functions are linked by the Kramer-Kronig relation, which is used to calculate the real part $\varepsilon_{1}(\omega)$ of the dielectric function derived from $\varepsilon_{1}(\omega)$ by the Kramers-Kronig transformation.

$$
\varepsilon_{1}(\omega)=1+\quad \frac{2}{\pi} \int_{0}^{\infty} d \omega^{\prime} \frac{\omega^{\prime} \varepsilon_{2}\left(\omega^{\prime}\right)}{\omega^{\prime} 2-\omega_{2}}
$$

The resulting dielectric function $\varepsilon$ is shown in Figure 6 as compared with experimental result in inset graph. As can be seen, Figure $6(\mathrm{~b})$, is focused on the imaginary dielectric function $\left(\varepsilon_{2}\right)$ where the experimental result demonstrated two clear peaks located at $1.65 \mathrm{eV}$ and $2.80 \mathrm{eV}$ while the calculated spectrum obtained three peaks. It is predicted that, at $1.13 \mathrm{eV}$ the transition could be due to $\mathrm{Co}^{3+}(\downarrow) \mathrm{t}_{2 \mathrm{~g}} \rightarrow \mathrm{Co}^{2+}(\downarrow) \mathrm{t}_{2 \mathrm{~g}}$. In this report, the transition which occurred could be by direct dipole-forbidden d-d transitions. These transitions (forbidden in the presence of perfect spherical symmetry) become allowed due to crystal-field splitting in the cubic spinel structure and due to hybridization of the oxygen $2 p$ states with the cobalt $3 d$ states [27][9]. Peaks at 2.15 and $2.63 \mathrm{eV}$ can be attributed to the ligand to metal transition between $\mathrm{O} 2 p$ and $\mathrm{Co}^{2+} / \mathrm{Co}^{3+} 3 \mathrm{~d}$ states. Due to larger oscillator strength of $\mathrm{p}-\mathrm{d}$ type excitation, these transitions are orders of magnitude stronger than $\mathrm{d}-\mathrm{d}$ type transition.

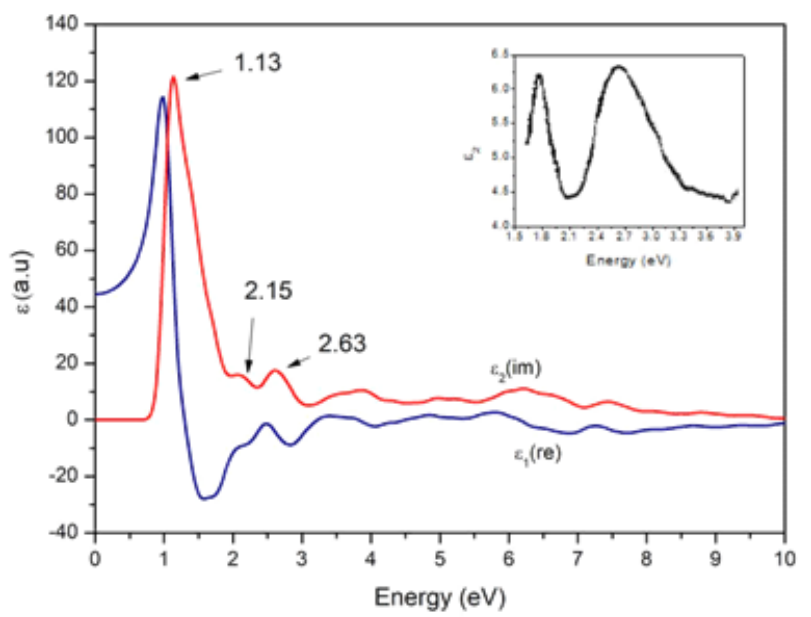

Figure 3 Imaginary parts of the dielectric function of $\mathrm{Co} 3 \mathrm{O} 4$ normal spinel (a) calculated and (b) inset experimental result [10] transitions between Co 3d. In this approach, the calculation predicted that the crystal field splitting at both octahedral and tetrahedral sites are of the same magnitude.

\section{Acknowledgement}

Authors would like to thank Ministry of Higher Education (MOHE) Malaysia for funding this research under the FRGS grant (600-IRMI/FRGS 5/3 (043/2017)) and Institute of Sciences, Universiti Teknologi MARA (UiTM) for the facilities provided.

\section{References}

[1] L. D. Kadam and P. S. Patil, "Thickness-dependent properties of sprayed cobalt oxide thin films," Mater. Chem. Phys., vol. 68, no. $1-3$, pp. 225-232, 2001

[2] J. Wöllenstein, M. Burgmair, G. Plescher, T. Sulima, J. Hildenbrand, H. Böttner, and I. Eisele,

[3] "Cobalt oxide based gas sensors on silicon substrate for operation at low temperatures,"

[4] Sensors Actuators, B Chem., vol. 93, no. 1-3, pp. 442-448, 2003

[5] B.-M. Chae, E.-S. Oh, and Y.-K. Lee, "Conversion mechanisms of cobalt oxide anode for Li-ion battery: In situ X-ray absorption fine structure studies,” J. Power Sources, vol. 274, pp. 748-754, 2015.

[6] S. Deng, X. Xiao, G. Chen, L. Wang, and Y. Wang, "Cd doped porous $\mathrm{Co} 3 \mathrm{O} 4$ nanosheets as electrode material for high performance supercapacitor application," Electrochim. Acta, vol. 196, pp. 316-327, 2016

[7] M. B. Durukan, R. Yuksel, and H. E. Unalan, "Cobalt Oxide Nanoflakes on Single Walled Carbon Nanotube Thin Films for Supercapacitor Electrodes," Electrochim. Acta, vol. 222, pp. 1475-1482, 2016.

[8] W. L. Roth, "The magnetic structure of Co3O4," J. Phys. Chem. Solids, vol. 25, no. 1, pp. 1-10, 1964

[9] S. A. Makhlouf, Z. H. Bakr, K. I. Aly, and M. S. Moustafa, "Structural, electrical and optical properties of Co3O4 nanoparticles," Superlattices Microstruct., vol. 64, pp. 107-117, 2013.

[10] L. Bai, M. Pravica, Y. Zhao, C. Park, Y. Meng, S. V Sinogeikin, and G. Shen, "Charge transfer in spinel Co $3 \mathrm{O} 4$ at high pressures," J. Phys. Condens. Matter, vol. 24, no. 43, p. 435401, 2012

A. F. Lima, "Interpretation of the optical absorption spectrum of $\mathrm{Co} 3 \mathrm{O} 4$ with normal spinel structure from first principles calculations," J. Phys. Chem. Solids, vol. 75, no. 1, pp. 148-152, 2014.

[11] K. J. Kim and Y. R. Park, "Optical investigation of chargetransfer transitions in spinel

[12] Co3O4," Solid State Commun., vol. 127, no. 1, pp. 25-28, 2003

[13] X.-L. Xu, Z.-H. Chen, Y. Li, W.-K. Chen, and J.-Q. Li, "Bulk and surface properties of spinel $\mathrm{Co} 3 \mathrm{O} 4$ by density functional calculations," Surf. Sci., vol. 603, no. 4, pp. 653-658, 2009.

[14] S. J. Clark, M. D. Segall, C. J. Pickard, P. J. Hasnip, M. I. J. Probert, K. Refson, and M. C.

[15] Payne, "First principles methods using CASTEP," Zeitschrift für Krist., vol. 220, no. 5-6-2005, pp. 567-570, 2005.

[16] D. M. Ceperley and B. J. Alder, "Ground state of the electron gas by a stochastic method,"

[17] Phys. Rev. Lett., vol. 45, no. 7, pp. 566-569, 1980.

[18] J. P. Perdew and A. Zunger, "Self-interaction correction to density-functional approximations for many-electron systems," Phys. Rev. B, vol. 23, no. 10, pp. 5048-5079, 1981

[19] J. P. Perdew and Y. Wang, "Accurate and Simple Analytic Representation of the Electron-Gas Correlation-Energy," Phys. Rev. B, vol. 45, no. 23, pp. 13244-13249, 1992.

[20] J. P. Perdew, K. Burke, and M. Ernzerhof, "Generalized Gradient Approximation Made

[21] Simple," Phys. Rev. Lett., vol. 77, no. 18, pp. 3865-3868, 1996

[22] J. P. Perdew, A. Ruzsinszky, G. I. Csonka, O. A. Vydrov, G. E. Scuseria, L. A. Constantin, X

[23] Zhou, and K. Burke, "Generalized gradient approximation for solids and their surfaces," vol.

[24] 136406, no. April, pp. 1-4, 2007

A. Louardi, A. Rmili, F. Ouachtari, A. Bouaoud, B. Elidrissi, and H. Erguig, "Characterization of cobalt oxide thin films prepared by a facile spray pyrolysis technique using perfume atomizer," J. Alloys Compd., vol. 509, no. 37, pp. 9183-9189, 2011. which is related to the absorption spectrum of $\mathrm{Co} 3 \mathrm{O} 4$ accounts for the charge transfer to be due to direct dipole-forbidden d-d 
B. S. Transactions, R. Manigandan, K. Giribabu, R. Suresh, L. Vijayalakshmi, A. Stephen, V.

[25] Narayanan, G. Campus, and G. Campus, "Cobalt Oxide Nanoparticles : Characterization and its Electrocatalytic Activity towards Nitrobenzene $\dagger$," vol. 2, pp. 47-50, 2013

[26] J. Chen, X. Wu, and A. Selloni, "Electronic Structure and Bonding properties of cobalt oxide in the spinel structure," Phys. Rev. B, vol. 83, pp. 245204-12, 2011.

A. Walsh, S.-H. Wei, Y. Yan, M. M. Al-Jassim, and J. A. Turner, "Structural, magnetic, and electronic properties of the $\mathrm{Co}-\mathrm{Fe}-\mathrm{Al}$ oxide spinel system: Density-functional theory calculations," Phys. Rev. B, vol. 76, no. 16, p. 165119, 2007.

[27] V. R. Shinde, S. B. Mahadik, T. P. Gujar, and C. D. Lokhande, "Supercapacitive cobalt oxide (Co3O4) thin films by spray pyrolysis,” Appl. Surf. Sci., vol. 252, no. 20, pp. 7487-7492, 2006.

[28] V. Singh and D. T. Major, "Electronic Structure and Bonding in Co-Based Single and Mixed Valence Oxides: A Quantum Chemical Perspective," Inorg. Chem., vol. 55, no. 7, pp. 3307-3315, 2016.

A. F. Lima, "Journal of Physics and Chemistry of Solids Interpretation of the optical absorption spectrum of $\mathrm{Co} 3 \mathrm{O} 4$ with normal spinel structure from fi rst principles calculations," J. Phys. Chem. Solids, vol. 75, no. 1, pp. 148-152, 2014.

[29] J. Chen, X. Wu, and A. Selloni, "Electronic Structure and Bonding properties of cobalt oxide in the spinel structure," Phys. Rev. B, vol. 83, pp. 245204-12, 2011.

A. Bouhemadou, F. Djabi, and R. Khenata, "First principles study of structural, elastic, electronic and optical properties of the cubic perovskite BaHfO3," Phys. Lett. A, vol. 372, no. 24, pp. 45274531, 2008.

[30] L. Qiao, H. Y. Xiao, H. M. Meyer, J. N. Sun, C. M. Rouleau, A A. Puretzky, D. B. Geohegan,

[31] N. Ivanov, M. Yoon, W. J. Weber, and M. D. Biegalski, "Nature of the band gap and origin of the electro-/photo-activity of Co3O4," J. Mater. Chem. C, vol. 1, no. 31, pp. 4628-4633, 2013. 